\title{
IMAGENS E FABULAÇÃO EM ENCONTROS COM PROFESSORAS
}

\author{
IMAGES AND FABULATION IN MEETINGS WITH TEACHERS
}

\author{
Ana Cláudia Santiago Zouain ${ }^{1}$ \\ Sandra Kretli da Silva ${ }^{2}$ \\ Nathan Moretto Guzzo Fernandes ${ }^{3}$
}

\begin{abstract}
Resumo: O presente texto problematiza: o que pode a imagem cinematográfica em encontro com professoras? Articula diferentes movimentos de professoras com as imagens cinema na tentativa de potencializar o pensamento em devires. Busca deslocar a imagem de uma educação dogmática, ao tecer linhas de fuga na composição de outras imagens de escola e de educação. O estudo constituise de movimentos de pesquisa cartográfica em escolas públicas do município de Vitória, ES. Em diálogo com Deleuze e Guattari, aposta nas redes de conversações com professoras no encontro com as imagens cinema, as quais se envolvem na produção de sentidos entre práticasdiscursivas, textos, narrativas, imagens, sons, silêncios e silenciamentos. As narrativas que emergem dos encontros com professoras, questionam as imagens de currículos, de docências e de infâncias que estão impostas para as escolas. Assim, o estudo aposta em diferentes imagens de pensamento como outras possibilidades de se pensar uma educação da diferença.
\end{abstract}

Palavras-chave: Formação de professoras; imagens cinematográficas; redes de conversações.

\begin{abstract}
The present text questions: what the cinematographic images can do in an encounter with teachers? It articulates different teacher movements with cinema images in an attempt to enhance thinking about becoming. It seeks to displace the image of a dogmatic education, by composing escape lines in the composition of other images of school and education. The study consists of cartographic research movements in public schools in the city of Vitória, ES. In dialogue with Deleuze and Guattari, it invests in networks of conversations with teachers in the encounter with cinema images, which are involved in the production of meanings between discursive practices, texts, narratives, images, sounds, silences and silences. The narratives that emerge from the meetings with teachers, question the images of curriculum, teaching and childhood that are imposed on schools. Thus, the study bets on different images of thought as other possibilities for thinking about an education of difference.
\end{abstract}

Keywords: Teacher training; cinematographic images; conversation networks.

\section{Por entre imagens cinema e imagens de escolas: diferentes composições possíveis...}

Lançamo-nos em composições com os signos artísticos do cinema para pensar: o que pode a imagem cinematográfica em encontro com professoras? Nosso objetivo se deu em articular diferentes movimentos de professoras com imagens cinematográficas na tentativa de potencializar o pensamento em devires. Buscamos provocar o pensamento a pensar para além de uma educação dogmática, tecendo linhas de fuga (DELEUZE; GUATTARI, 1995) na composição de uma educação com a diferença, ou ainda, de uma educação que busca afirmar a vida em toda a sua potência, em toda a sua multiplicidade.

Nosso estudo constituiu-se de movimentos de pesquisa cartográfica em escolas públicas do município de Vitória, ES. Apostamos na potência das imagens cinema (DELEUZE, 2015)

\footnotetext{
${ }^{1}$ Universidade Federal do Espírito Santo.

${ }^{2}$ Universidade Federal do Espírito Santo.

${ }^{3}$ Universidade Federal do Espírito Santo.
} 
em redes de conversações (CARVALHO, 2009) com professoras como força que impulsiona o pensamento. Os encontros de professoras com as imagens cinematográficas provocam afecções e percepções que se envolvem na produção de sentidos entre práticasdiscursivas, textos, narrativas, sons, silêncios e fabulação. As cartografias foram disparadas nos processos de formação de professoras, buscando questionar as imagens de currículos, de docências, de infâncias e de escolas, lançando, assim, outros possíveis para a educação.

Apostamos ainda que os encontros são acontecimentos que deslocam um corpo a pensar, visto que o pensamento não é dado como algo natural, mas violentado pelos agenciamentos coletivos que atravessam os corpos, sejam por meio de textos que foram lidos, de filmes que foram assistidos, de aulas, de conversas, enfim, por uma multiplicidade de encontros.

Para o nosso estudo, os encontros com as imagens cinematográficas seguidos de redes de conversações com as professoras foram realizados semanalmente, de forma remota, devido ao contexto de pandemia que estamos vivenciando desde março de 2020, por conta do novo coronavírus (Covid-19). Sendo assim, nos organizamos juntamente com as escolas para compor dentro das possibilidades que essa nova situação nos exigia.

Assim, como disparador para as redes de conversações com as professoras, selecionamos diversos curtas-metragens na tentativa de violentar o nosso pensamento. Para este artigo, selecionamos a animação japonesa Children ${ }^{4}$, produzida em 2011, sob a direção de Takuya Okada. O curta Children possui signos ópticos e sonoros que nos deslocam em possibilidades outras de pensamento, e podem ainda, quebrar alguns clichês que foram impostos para a escola e para a educação, provoca-nos inquietações e desejos de fabular outros modos de vida para as infâncias, para as docências e para os cotidianos escolares.

Para Machado (2009, p. 294), a “[...] imagem óptica e sonora pura revela o que não se vê, o imperceptível". Elas podem produzir novas problematizações para as políticas curriculares em ação e ainda, criar processos de resistências coletivas articuladas com as fabulações das infâncias e das docências inventivas.

Ressaltamos a força das imagens cinema em encontros de formação de professoras, pois possibilitam fabular novas imagens de escolas. As redes de conversações com as imagens cinematográficas nos permitem enredar composições com os afetos que pedem passagem (ROLNIK, 2007), e nos dão pistas para desdobrar a educação para além daquilo que já está prescrito, na tentativa de engendrar sentidos entre olhares, gestos, falas, pausas, balanços de corpos-pensamentos que vibram com as imagens, as docências, os currículos e os encontros-acontecimentos.

\section{Reverberações no pensamento em devires: por outras imagens de currículos, de docências e de infâncias}

Uma música funesta, transcorrendo junto aos sons de passos largos e acelerados sem tempo a perder e a passagem de um trem em meio aos transeuntes de uma estação abrem o curta-metragem. Imagens cinzas se entrelaçam com cenas de poluição e sensação de ar que sufoca. Vidros se espatifam, desespero, medo, revolução. O terror parece rondar, como um espectro que está no ar!

Uma cidade fabril é o cenário do filme, fabril também é o modo de funcionar da escola em Children, com estudantes uniformizados, todos com o mesmo tempo para executar as tarefas, as mesmas metas de aprendizagem, a cobrança por eficiência e resultados padronizados. Esta paisagem triste que pretende o apagamento das singularidades e multiplicidades que compõe a vida, evoca uma insurreição.

\footnotetext{
${ }^{4}$ Curta-metragem Children disponível em: https://www.youtube.com/watch?v=BE4oz2u6OHY.
} 
O uso da arte-cinema em meio a redes de conversações tem sido um modo de, coletivamente, deslocar o pensamento, de abrir rasgões para que forças intensivas expandam as possibilidades para docências inventivas. Por isso, os encontros são tecidos em cooperação com as professoras, que também trazem problematizações acerca daquilo que atravessa a escola, as práticas docentes, as políticas curriculares, os afazeres burocráticos e os processos de aprendizagem.

Nesse sentido, buscamos cartografar os efeitos de pensamentos que emergem nas experimentações com o cinema; bem como entender que sentidos provocam para a composição de territórios existenciais de currículos; questionando as relações entre imagens-cinema, estudantes e professoras na abertura do campo dos possíveis para pensar a educação.

Após a exibição do curta-metragem Children, uma série de narrativas já avolumavam o chat do aplicativo no qual se deu a nossa formação online. A partir delas vimos que a ex-posição e a potência da imagem filme possibilitou a abertura para uma rede de afectos e conversações que, ao quebrar o silêncio, fez emergir imagens de pensamentos que problematizam as docências, os currículos, as infâncias, enfim, as imagens de escola.

"Inquietador!! O filme nos mostra de forma perturbadora a rotina escolar de crianças idênticas, numeradas e com zíperes no lugar das bocas. Vejo como uma amarga e tenebrosa crítica à educação e provoca inúmeras inquietações. O que pode ser esse cachorro preto? E o trem, o que ele suscita? E as máscaras dos/nos professores? Vou ter que assistir mil vezes e ficar horas a fio pensando e conversando... Multiplicidade de sensações e de sentimentos".

"O vídeo me faz pensar como o objetivo das escolas parece que vem sendo a busca da perfeição. As crianças não podem ser crianças (rir, brincar, se divertir, errar, cair, fantasiar) elas têm que ser "boas", TODAS elas, de preferência IGUAIS. Talvez, por isso o placar sempre é 10 a 10, porque todos têm a mesma obrigação: "serem perfeitos". Os números nas cabeças das crianças, me dá a sensação de que eles não são vistos como pessoas, mas, sim, como máquinas despersonalizadas que carregam o fardo de serem gênios em tudo o que faz. São apenas números, tanto para a escola, quanto para a sociedade”.

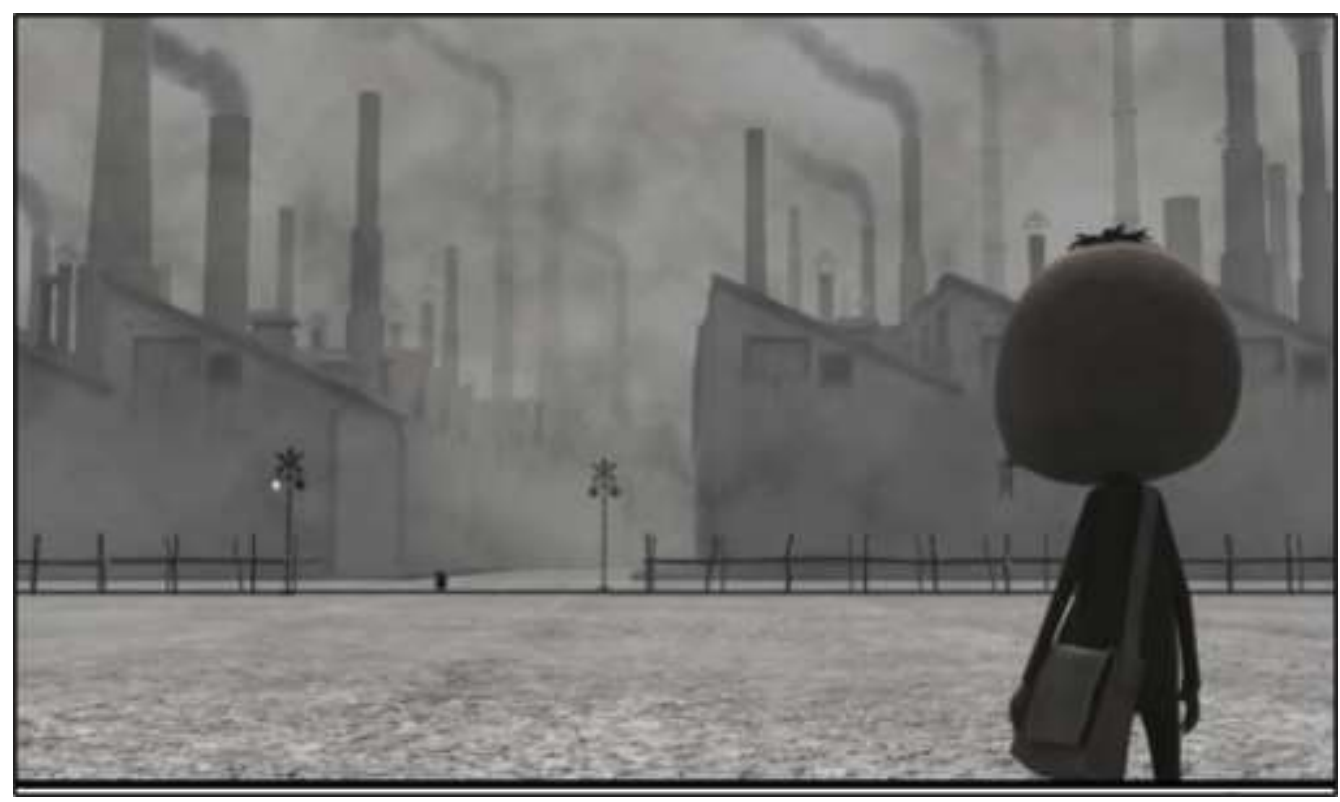

Imagem 1: Atravessamentos... - Fonte: https://filmow.com/children-t205668/ 


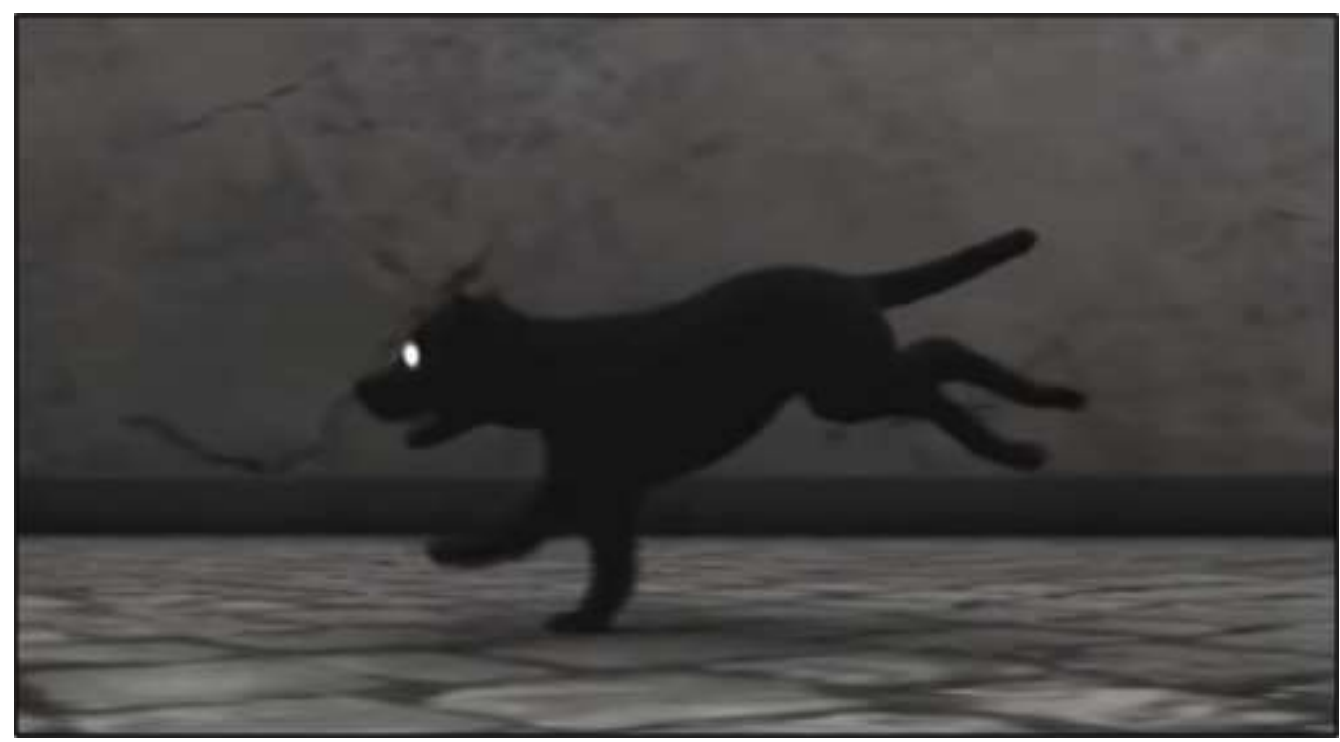

Imagem 2: O cachorro - em busca de linhas de fuga, desvios, válvulas de escape...

Fonte: https://filmow.com/children-t205668/

Ao entrarem em relação com as imagens do curta, as professoras apresentam indagações que fazem questionar o modelo rígido, fixado, recognitivo e disciplinar de ensino que caracteriza muitas escolas, pois este modelo acaba, em seu limite, por tentar impedir que outras subjetividades, outros modos de fazer/ser/estar escola insurjam.

Nesta linha, as professoras insistem que este modo de funcionar da escola e toda essa maquinaria de controle que vem sendo construída historicamente precisa ser revista, quebrada. Nas narrativas, as professoras traçam conexões com suas experiências no passado como estudantes, agora como professoras, associam a imagem filme com a realidade concreta de suas escolas, numa atualização contínua que produz imagens pensamentos para pensar outros possíveis na escola.

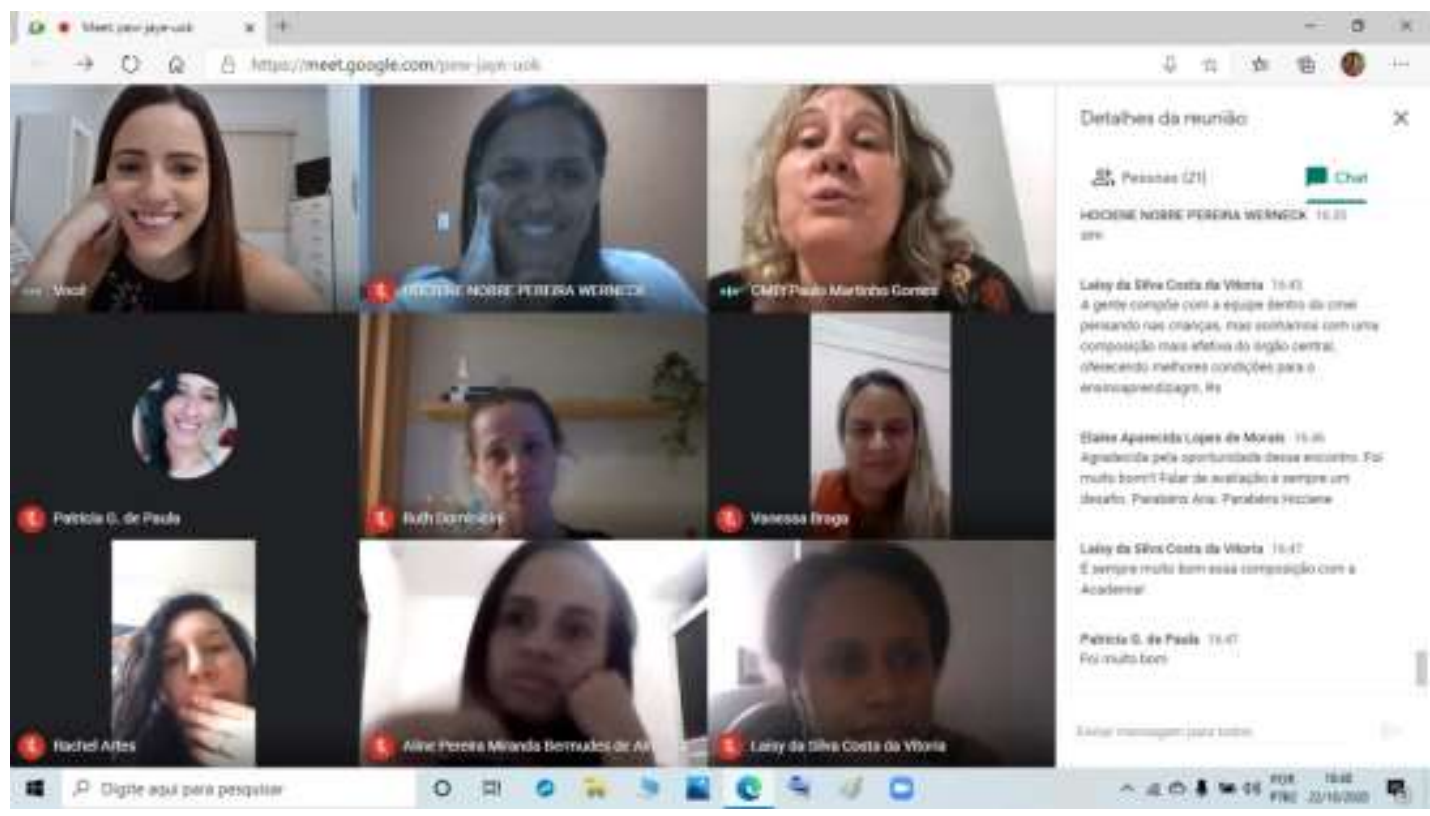

Imagem 3: Encontro remoto de formação de professoras e as reverberações no chat.

Fonte: arquivo dos autores. 
"O modelo de alunos que a sociedade capitalista deseja: alunos adestrados, alienados e que não questiona o sistema, mas, sim, aceita. Me lembrei da minha época de colegial, onde ficar de castigo e ser afligido com palmatorias era comum, onde a imposição era mais forte e rígidos, o medo de falar era maior do que o castigo dos pais. Eu tinha mais medo do professor do que do meu pai".

"Fazendo uma aproximação dos vídeos com a realidade, vemos que muitas escolas ainda perpetuam esse sistema de ensino que prioriza mais o resultado, do que o processo subjetivo de cada aluno. Nessa perspectiva, a escola acaba funcionando como um sistema fabril e o alunos buscam a todo tempo se enquadrar no modelo ideal que a escola espera que seja alcançado por eles. Nesse processo, as falas e pensamentos dos educandos não são priorizadas, a manifestação de habilidades em outras áreas artísticas não é considerada, pois o que importa é se nos testes avaliativos as notas altas estão sendo alcançadas".

"É preciso quebrar com essa linha teórica de reprodução de conhecimento e comportamento, em que o currículo e as escolas (padronizadas) não impeça os docentes de ter um olhar sensivel para o aluno, e olhe para além de fichas e notas".

De certo, nem tudo no pensamento e no cotidiano escolar é novidade, no plano de imanência há muito mais processos de recognição do que de criação. Uma maquinaria de práticasdiscursivas que como um vírus em um corpo, colonizam os territórios escolares, e acabam automatizando as práticas docentes: a cumprir o tempo cronometrado, a expor apenas os conteúdos ditos essenciais, a esvaziar o armário das atividades previstas, para, assim, recomeçar o dia seguinte com a mesma rotina, sem olhar para o campo de possibilidades "para além de fichas e notas", conforme lembrou a professora.

Em contrapartida, o seguir das conversações nos apontam para possibilidades de perfurar esta forma-escola enrijecida, dogmática, fazendo com que o pensamento explore outros eixos de sentidos, diferente daqueles que lhe fixam ao lugar comum. Para deslocar o pensamento em devires, como nos ensina Deleuze (2015), ou conforme também sugere Brito, "para além de um pensamento apaziguador" (BRITO, p. 69, 2019).

"No filme, o cachorro parece representar atitudes livres que gostaria de tomar, mas, sempre é cortado pelo trem (o sistema escolar). Por fim ele consegue abraçar seu cão e é atropelado pelo trem relacionando a reação do opressor, ele cai sangrando, mas feliz por ter feito o que queria, por se libertar do lugar que oprimia”.

“Entretanto, em sua parte final o curta possibilita pensarmos que é sempre muito difícil para as escolas se perpetuarem impondo o seu desejo de controle para muitas pessoas por um período longo de tempo, e que é chegada uma hora em que esses sujeitos vão começar a questionar o porquê deste modelo e não de outros".

"No final, a explosão dos zíperes demonstra metaforicamente a revolução dos alunos, que se sentiam aprisionados. O curta termina com um aluno, que após ser atropelado por salvar o cachorro, começa a rir. O que pude inferir a partir dessa cena, é que o menino pela primeira vez, experienciou uma situação diferente em sua vida. Ele finalmente conseguiu sentir-se vivo. A risada final demonstra liberdade".

A explosão dos zíperes, a fuga do menino para abraçar o cachorro, a risada, cenas do final do filme são tomadas pelas professoras como práticas de liberdade em meio a falta de cor do 
caos. Possibilidades de insurreição ante aquilo que visa apequenar a vida em sua potência expansiva. Ao fazerem esta conexão, elas extraem a potência das imagens para fazer com elas vidência, pois a explosão dos zíperes é uma eclosão de vida.

Para Deleuze (2015), o vidente ou visionário é aquele que vê no cristal a imagem em suas duas faces, atual e virtual, o presente e o passado, a dobra do tempo, a representação e a diferença. Só o vidente consegue extrair dos clichês a verdadeira imagem, uma imagem pura e inventiva, imagem de vidência, imagem-vida.

Por vezes é preciso restaurar as partes perdidas, reencontrar tudo o que não se
vê na imagem, tudo o que se lhe subtraiu para a tornar "interessante". Mas por
vezes, pelo contrário, é preciso fazer buracos, introduzir vazios e espaços
brancos, rarefazer a imagem, suprimir-lhe muitas coisas que tinham sido
acrescentadas para nos fazer crer que víamos tudo. Há que dividir ou fazer o
vazio para reencontrar o inteiro (DELEUZE, 2015, p. 38-39).

$\mathrm{Na}$ busca de quebrar o clichê para extrair uma imagem pura inventiva, nos deparamos com o vazio. Quando a imagem aparentemente se esgota e faz com que fabulamos outras imagens, provocando outros possíveis, pois o vazio da imagem pode muitas composições.

$\mathrm{Na}$ cena da explosão dos zíperes, as professoras tornam-se videntes pois mergulham nas imagens de Children, por entre uma criança que, num mundo cinza, resiste sensível à vida, que abraça como modo rebelar, que inventa modos de viver em meio ao caos e, por entre docentes que veem no cristal do tempo o duplo de imagens, a coalescência do passado e do presente. Cenas de um filme-vida que movimentaram seus corpos em devires-pensamentos, provocando o despertamento dos clichês para o encontro com uma imagem de vida.

\section{Em movimentos sem fim... Por diferentes imagens na composição de uma educação da diferença}

O interesse pelas imagens cinematográficas como disparadoras de movimentos de pensamento com o cotidiano escolar se deu na tentativa de deslocar algumas verdades impostas pela educação dogmática, possibilitando outras maneiras de se pensar a escola. O corpoescola ao entrar em conexão com as imagens, apresenta as suas sensações, percepções e afecções, pulsa linhas de vida que reverberam sentidos nos corpos-pensamentos de professoras que foram tocados com a força das imagens.

Para Deleuze (1987, p. 96), “o que nos força a pensar é o signo. O signo é objeto de um encontro; mas é precisamente a contingência do encontro que garante a necessidade daquilo que ele faz pensar". A casualidade do encontro produz o pensamento, ele é movido pelo imprevisível, por aquilo que não se conhece, impulsionado pelo devir inventivo de um novo pensamento que se tece.

Corroborando ainda com Deleuze, o texto lança-se na composição com os signos artísticos do cinema, disparando imagens de pensamento de professoras no encontro com diferentes imagens cinematográficas. Para o autor, a "[...] imagem cinematográfica tem de ter um efeito de choque sobre o pensamento e forçar o pensamento a pensar-se a si mesmo e a pensar o todo. É a própria definição do sublime” (DELEUZE, 2015, p. 249).

Sendo assim, não é possível determinar de antemão o que acontecerá em um encontro, pois este é da ordem do acaso. Deleuze (1987) afirma que é a imprevisibilidade do encontro que movimenta o pensamento a problematizá-lo, e assim, há a verdadeira criação. Pensar com as imagens desloca o pensamento de seu sentido habitual apreendido, pois o corpo se move pela potência da fabulação. 
Quando um corpo se põe a fabular, há uma falsificação das verdades pré-estabelecidas, um possível distanciamento da narrativa veraz, para a abertura da potência do falso das imagens.

A fabulação é da ordem de um tempo intensivo que não se mensura em representação, mas se desdobra pela invenção, "a fabulação criadora nada tem a ver com uma lembrança mesmo amplificada, nem com um fantasma. Com efeito, o artista, entre eles o romancista, excede os estados perceptivos e as passagens afetivas do vivido [...]" (DELEUZE, GUATTARI, 2000 , p. 222). As imagens-cinema criam o impensável no pensamento nos quais as professoras fabulam diferentes imagens de escola, impulsionando imagens de vida.

O pensamento movente se potencializa pelos diferentes encontros de uma educação que nunca se restringe, mas sempre se reinventa. Uma educação que se permite deslocar para além das superfícies do habitual, ampliando sentidos outros pela potência da fabulação, pois "o ato de pensar não decorre de uma simples possibilidade natural; é, ao contrário, a única criação verdadeira (DELEUZE, 1987, p. 96).

Assim, o corpoescola é produzido a todo o momento, em meio aos acontecimentos que o cercam e que perpassam os encontros pelos quais desdobram-se diferentes linhas de pensamento, de invenção, de resistência, enfim, de movimentos insurgentes de vida por uma educação filosófica da diferença que movimenta os corpos a pensar, a criar e a re-existir.

\section{Referências}

BRITO, Maria dos Remédios. Da geografia do pensamento. In: BRITO, M. R.; COSTA, D. W. S. (Org.). Variações Deleuzianas. Educação e pensamento e política e fabulação e... Belém, PA: EditAedi, 2019.

CARVALHO, Janete Magalhães. O cotidiano escolar como comunidade de afetos. Rio de Janeiro: DP\&A; Brasília, DF: CNPq, 2009.

DELEUZE, Gilles. A imagem-tempo: cinema 2. 1985. Tradução de Sousa Dias. 1. ed. Lisboa, Portugal: Documenta, 2015.

DELEUZE, Gilles. Proust e os signos. Tradução de Antônio Picquet e Roberto Machado. Rio de Janeiro: Forense Universitária, 1987.

DELEUZE, Gilles; GUATTARI, Félix. Mil Platôs: capitalismo e esquizofrenia. v. 1. Rio de Janeiro: Ed. 34, 1995.

DELEUZE, Gilles; GUATTARI, Félix. O que é a filosofia? Rio de Janeiro: Editora 34, 2000.

MACHADO, Roberto. Deleuze, a arte e a filosofia. Rio de Janeiro: Jorge Zahar Ed., 2009.

ROLNIK, Suely. Cartografia sentimental: transformações contemporâneas do desejo. São Paulo: Estação Liberdade, 2007.

\section{Sobre os autores}

Ana Cláudia Santiago Zouain. Mestre em Educação pela Universidade Federal do Espírito Santo. Professora da Rede Municipal de Vitória-ES.

E-mail: aninhazouain@gmail.com. 
Sandra Kretli da Silva. Professora Adjunta do Departamento de Teorias e Práticas do Ensino da Ufes, do Programa de Pós-Graduação de Mestrado Profissional em Educação (PPGMPE) e do Programa de Pós-Graduação em Educação (PPGE) da Ufes.

E-mail: sandra.kretli@hotmail.com.

Nathan Moretto Guzzo Fernandes. Mestre em Educação pela Universidade Federal do Espírito Santo. Professor de Geografia da Rede Estadual de Ensino, em Vitória/ES.

E-mail: nathanmoretto1@ hotmail.com. 